\title{
Study on Fire Smoke Distribution and Smoke Control in Extra-long Double-hole Tunnel
}

\author{
Jingdan $\mathrm{Gan}^{1}$, Fengshan $\mathrm{Wu}^{2}$ \& Hong $\mathrm{Liu}^{1}$ \\ ${ }^{1}$ School of the Environment and Safety Engineering, Jiangsu University, Zhenjiang, Jiangsu, China \\ ${ }^{2}$ Institute of Testing, JSTI Group, Nanjing, Jiangsu, China \\ Correspondence: Fengshan Wu, Institute of Testing, JSTI Group, Nanjing, Jiangsu, China. E-mail: wfs360@ \\ jsti.com
}

Received: November 28, 2020; Accepted: December 16, 2020; Published: December 21, 2020

\begin{abstract}
Tunnels are considered as one of the main methods to solve physical traffic barriers. However, It vulnerable to the threat of fire during the process of tunnel operation period. In response to such situation, this article explores the smoke distribution of extra-long double-tube tunnel and its impact on evacuation in the event of a fire. This paper take the Jieling tunnel as an example, and applies Accident Tree Analysis (ATA) method combined with Fires Dynamics Simulator (FDS)simulation software to study the changes of harmful factors such as tunnel smoke. Finally, the function of air curtain in the control of smoke is analyzed. The calculation results show that: the structure of the double-hole extra-long tunnel and air curtain could help people have enough time to escape.
\end{abstract}

Keywords: tunnel fire, accident tree analysis, fires dynamics simulator, smoke control

\section{Introduction}

With the rapid development of highway construction in central and western China, the number of extra-long tunnels has been continuing to increase. Although the possibility of fires is relatively low, considering that extralong highway tunnels are usually away from cities, together with the fact that their long linear semi-enclosed structures tend to add difficulties in smoke discharge, rescue, and evacuation, the fire control for extra-long highway tunnels are confronted with more severe challenges compared with urban situation (Hitoshi, et al., 2003; Chow, et al., 2015; Li, 2013).

There has already been theoretical and experimental research of tunnel fires long time ago, and many meaningful experiments were carried out on ventilation and evacuation. In the 1960s, the smoke control theory was first proposed by PLARC (World Road Association, 1999). Designed by the US Highway Administration, the MTFVTP plan was used to conduct experiments on a 50-meter abandoned highway tunnel through a camera to obtain the design plan of the ventilation system (Brinckerhoff, 2005). The diversification of tunnel equipment and constantly changing conditions complicates the problem of smoke discharge, recently, many scholars have made use of tunnel fire experiments to carry out various beneficial research results, not only ventilation system linkage control schemes and the effect of critical velocity on smoke control (Zhuang, et al., 2020; Vauquelin, et al., 2005), but also Deluge system and ventilation way have important impact to control the development of the fire $(\mathrm{Xu}$, et al., 2010; Cheong, et al., 2014).

Compared with experimental research, computer simulation can be applied to more complex tunnel environments more quickly and efficiently. The visibility and temperature of smoke are the most important factors for safe evacuation of the personnel (Lin., 2008; Gu, et al., 2008). People usually had good situation awareness and judgment in tunnel fire (Horikoshi, 2009; Max, et al., 2015). Roof ventilation and vehicle congestion have shown some impacts to the change of smoke flow (Soufien, et al., 2017; Harish, et al., 2014). The model which was used for assessing tunnel life safety was also constructed with mathematical analysis and time-distance diagrams (Gehandler, et al., 2015).

The structure of the double-hole extra-long tunnel is obviously different from that of the conventional single-hole tunnel, and its structure may cause changes in smoke transmission. When a fire breaks out in a certain position of the long double-hole tunne, the air above the ignition will be heated instantly, leading to the temperature rising and the lower air density. At this time, the air will continue to rise and inhale the surrounding fresh air. During the rising process, it will spread to the surrounding areas after encountering the inner wall of the tunnel. At the long 
distance from the fire, the smoke will spread to a wider space and even to the horizontal direction Holes. Therefore, this article starts from the construction of the Jieling extra-long double-hole tunnel and explores its evacuation method in the event of a fire. First, the ATA method was used to classify and rate the cause of the fire where the truck was used as the main cause of the tunnel fire. Combined with FDS simulation software, it simulated the smoke distribution and temperature changes, toxic gas concentration and other change of the tunnel in the Jieling Tunnel after a disaster caused by a truck fire and finally analyzed the effect of cross-passages and air curtains on blocking smoke, and analyzed their effects on the safe evacuation of personnel.

\section{Method}

\subsection{ATA}

Accident Tree Analysis (ATA) is an analysis method that originated from the Fault Tree Analysis (FTA), it is a method of starting from the analyzed specific accident, analyzing the cause of the occurrence, and finding the basic cause of the accident (Laurent, et al., 2018). The basic causes are also called basic events, which refer to those situations where statistics or data are known. The ATA method is used here to more comprehensively evaluate various unsafe events during the operation of tunnel fires, and then understand the incidence of each event through the minimum cut set, as shown in Figure 1, and Table 1.

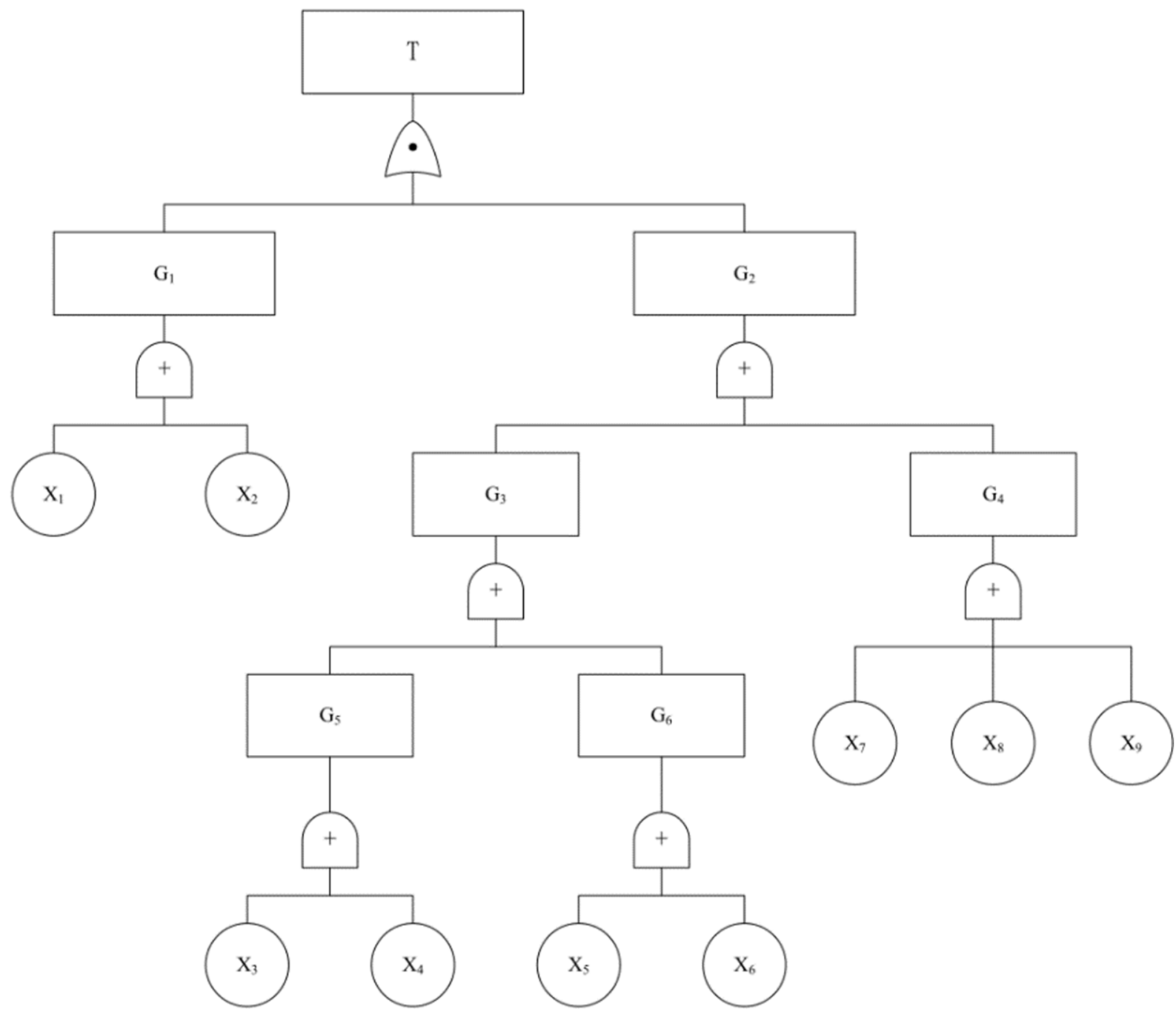

Figure 1. The accident tree of tunnel fire 
Table 1. Basic event table

\begin{tabular}{ll}
\hline Number & Basic event \\
$T$ & Tunnel fire \\
$\mathrm{G}_{1}$ & Ignition source \\
$\mathrm{G}_{2}$ & Flammable substances \\
$\mathrm{G}_{3}$ & External transport material catches fire \\
$\mathrm{G}_{4}$ & The equipment inside the tunnel caught fire \\
$\mathrm{G}_{5}$ & Vehicle catches fire \\
$\mathrm{G}_{6}$ & The cargo catches fire \\
$\mathrm{X}_{1}$ & Artificial \\
$\mathrm{X}_{2}$ & Non-artificial \\
$\mathrm{X}_{3}$ & The vehicle caught fire \\
$\mathrm{X}_{4}$ & The vehicle caught fire \\
$\mathrm{X}_{5}$ & Spontaneous combustion of combustibles \\
$\mathrm{X}_{6}$ & Ignited \\
$\mathrm{X}_{7}$ & Fan caught fire \\
$\mathrm{X}_{8}$ & Transmission line caught fire \\
$\mathrm{X}_{9}$ & Distribution box caught fire \\
\hline
\end{tabular}

Minimum cut set:

$$
\begin{aligned}
\mathrm{T} & =\mathrm{G}_{1} \times \mathrm{G}_{2} \\
& =\mathrm{X}_{1}+\mathrm{X}_{2} \mathrm{G}_{3}+\mathrm{G}_{4} \\
& =\mathrm{X}_{1}+\mathrm{X}_{2} \mathrm{G}_{5}+\mathrm{G}_{6}+\mathrm{G}_{4} \\
& =\mathrm{X}_{1}+\mathrm{X}_{2} \mathrm{X}_{3}+\mathrm{X}_{4}+\mathrm{X}_{5}+\mathrm{X}_{6}+\mathrm{X}_{7}+\mathrm{X}_{8}+\mathrm{X}_{9} \\
& =\mathrm{X}_{1} \mathrm{X}_{3}+\mathrm{X}_{1} \mathrm{X}_{4}+\mathrm{X}_{1} \mathrm{X}_{5}+\mathrm{X}_{1} \mathrm{X}_{6}+\mathrm{X}_{1} \mathrm{X}_{7}+\mathrm{X}_{1} \mathrm{X}_{8}+\mathrm{X}_{1} \mathrm{X}_{9}+\mathrm{X}_{2} \mathrm{X}_{3}+\mathrm{X}_{2} \mathrm{X}_{4}+\mathrm{X}_{2} \mathrm{X}_{5}+\mathrm{X}_{2} \mathrm{X}_{6}+\mathrm{X}_{2} \mathrm{X}_{7}+\mathrm{X}_{2} \mathrm{X}_{8}+ \\
& \mathrm{X}_{2} \mathrm{X}_{9}
\end{aligned}
$$

After Boolean algebra calculations, 14 groups of basic events of fire accidents are obtained. Each minimum cut set represents one possible event. The more the minimum cut sets, the more likely the accident will occur. This also shows that highway tunnel fires are extremely prone to take place. Among them, there are four bottom events related to vehicle fires and cargo fires $\left(\mathrm{X}^{3}, \mathrm{X}^{4}, \mathrm{X}^{5}, \mathrm{X}^{6}\right)$, that is, there are 8 minimum cut set combinations, which together account for $57 \%$ of all incidents. Therefore, freight trucks are more likely to be the main danger one of the sources.

The selection of the fire source refers to the National Fire Protection Association 502 Standards (NFPA 502-2017, 2017), which stipulates that the heat release of trucks is 20-30MW. According to China's current "Code for Design of Ventilation and Lighting of Highway Tunnels", the recommended smoke exhaust velocity during a tunnel fire is $2 \sim 3 \mathrm{~m} / \mathrm{s}$, based on the fact that the heat release of the fire under normal circumstances is $20 \mathrm{MW}$ (JTG/T D70/202-2014).

Therefore, the fire scale simulated in this article is also a medium-sized fire. The fire source model selects the freight trucks that are most prone to fires. It can be assumed that the transportation mileage of such trucks is more than $1000 \mathrm{~km}$, the maximum cargo box length is 14.5 meters, and the interior width of the vehicle is about $2.4 \sim 3.0$ $\mathrm{M}(\mathrm{GB} / \mathrm{T} 3730.1,2001)$. For the convenience of calculation, this article sets the size of the fire source to $15 \times 3 \times 3 \mathrm{~m} 3$, and the heat release power of the fire source in the maintenance phase is set to $22.5 \mathrm{MW}$.

\subsection{Establishment of Tunnel Calculation Model}

This article uses Fires Dynamics Simulator software, which mainly includes 2 parts: FDS calculation and SmokeView (Mcgrattan, et al., 2013). FDS is the core part of the simulation software whose main function is to complete the construction of simulation scenarios and actual numerical calculations; while SmokeView is a postprocessing program of FDS, which can be used to process calculation results, including dynamic data processing and static data display, displaying these static and dynamic data. By using FDS software and setting parameters, we can establish the parameter "slice" or control section of the entire model. Through the slice or section, we can visually observe the distribution of temperature, gas, and smoke in the building structure. 


\subsubsection{Setting of Tunnel Model}

The Jieling Tunnel is located at the junction of Yiling District, Xingshan County, Yichang City, Hubei Province. It is an extra-long double-hole tunnel on the Yiba Expressway in Hubei Province and is a key control project across the line. This article simplifies the cross-section drawing (Figure 2) and the plan design drawing (Figure 3) of the Jieling Tunnel as follows through field investigation and literature review. Among the specific parameters, the left line of the tunnel has a total length of $5653 \mathrm{~m}$, the right line has a total length of $5681 \mathrm{~m}$, the radius of the lining is $8.00 \mathrm{~m}$, and the radius of the inner arch is $5.60 \mathrm{~m}$. There are 6 cross-passages for vehicles, the longitudinal control spacing is $750 \mathrm{~m}$, and the boundary of the cross-passages for vehicles is set to: $4.5 \mathrm{~m}$ (width) $\times 5.0 \mathrm{~m}$ (height).

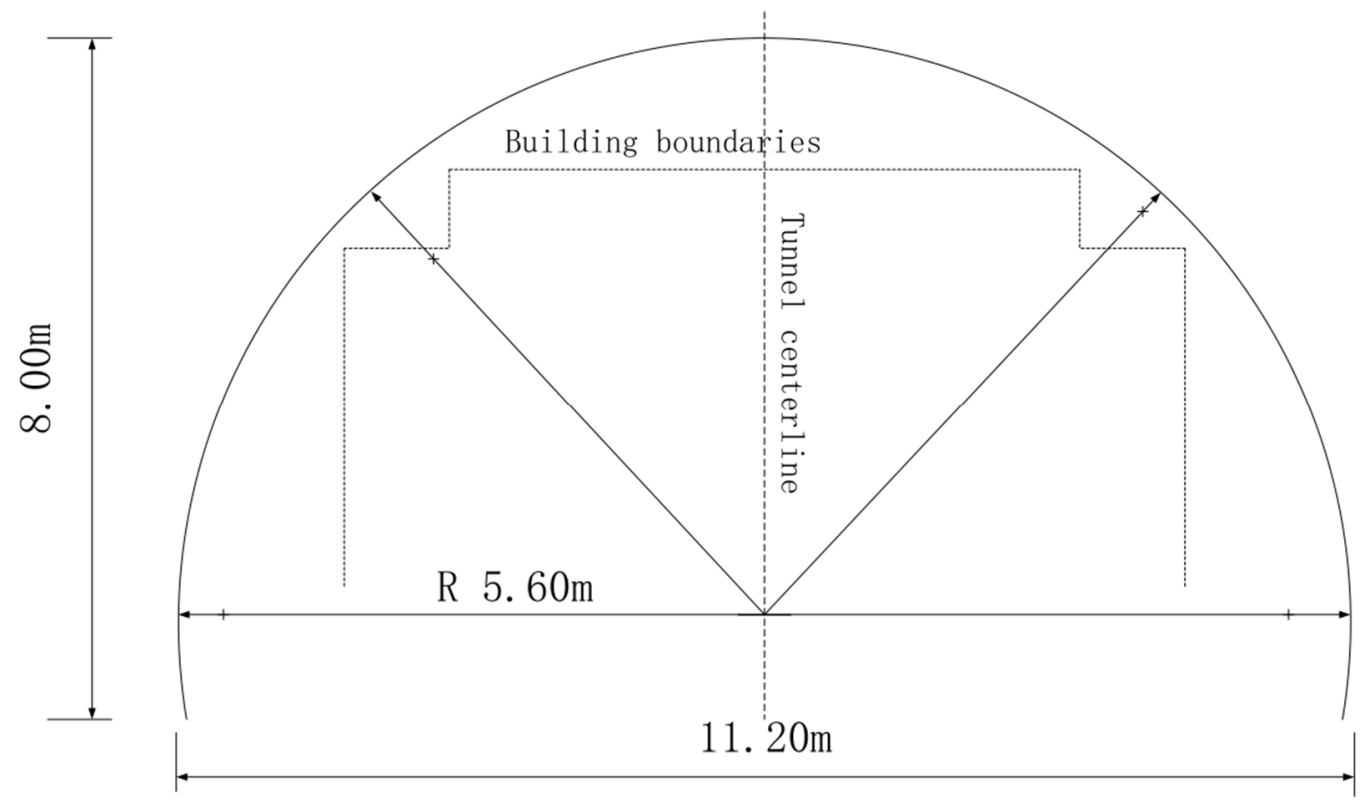

Figure 2. Cross section of Jieling tunnel

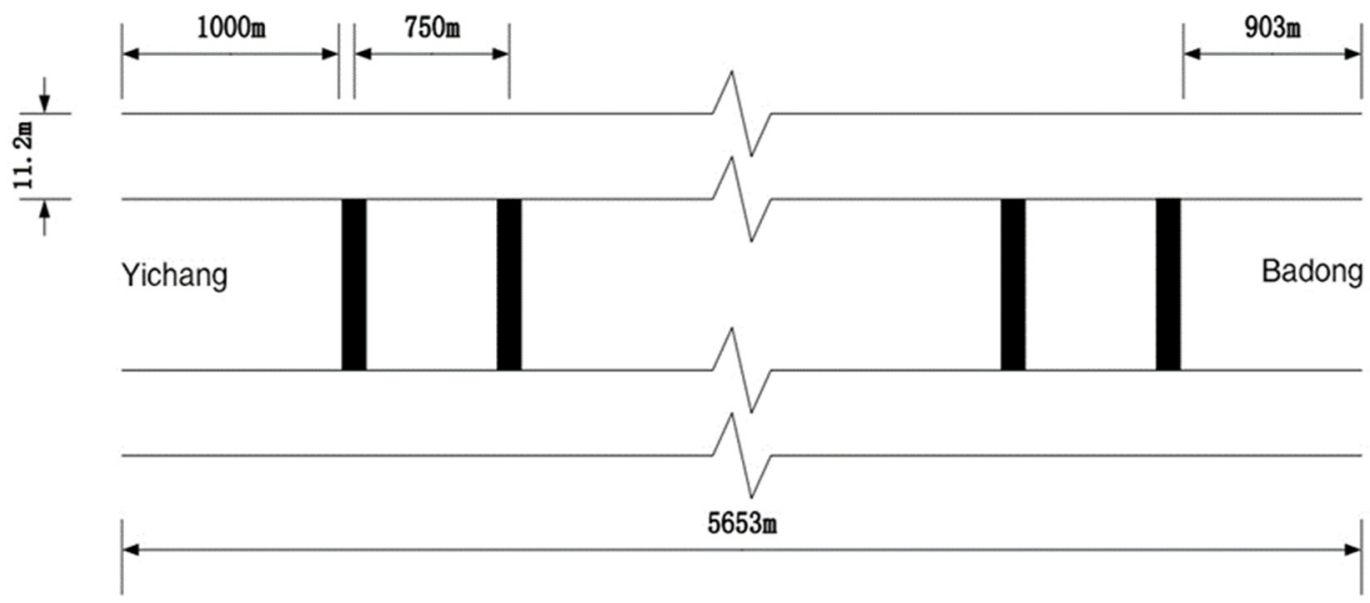

Figure 3. Schematic diagram of the plane design of Jieling tunnel

\subsubsection{Boundary Conditions and Meshing}

Tunnel ambient temperature: $16.9^{\circ} \mathrm{C}$; tunnel concrete temperature: $16.9^{\circ} \mathrm{C}$; tunnel air density: $1.225 \mathrm{~kg} / \mathrm{m}^{3}$; tunnel relative pressure: $0 \mathrm{~Pa}$ (atmospheric pressure is set to $1.01325 \times 10^{5} \mathrm{~Pa}$ ); tunnel entrance initial wind speed: 0.9898 $\mathrm{m} / \mathrm{s}$; exhaust speed near tunnel fire source: $3 \mathrm{~m} / \mathrm{s}$; gravity coefficient: $-9.81 \mathrm{~m} / \mathrm{s} 2$; tunnel entrance: constant velocity boundary condition; surface roughness coefficient of tunnel lining wall: 0.03 ; tunnel wall surface: solid wall boundary condition. In order to make the flow field more stable, the grid size is set to $0.5 \times 0.5 \times 0.5$. As shown in 
Fig. 4, a full-scale model of the Jieling Tunnel is established. The tunnel model is divided into left and right holes and cross-passages.

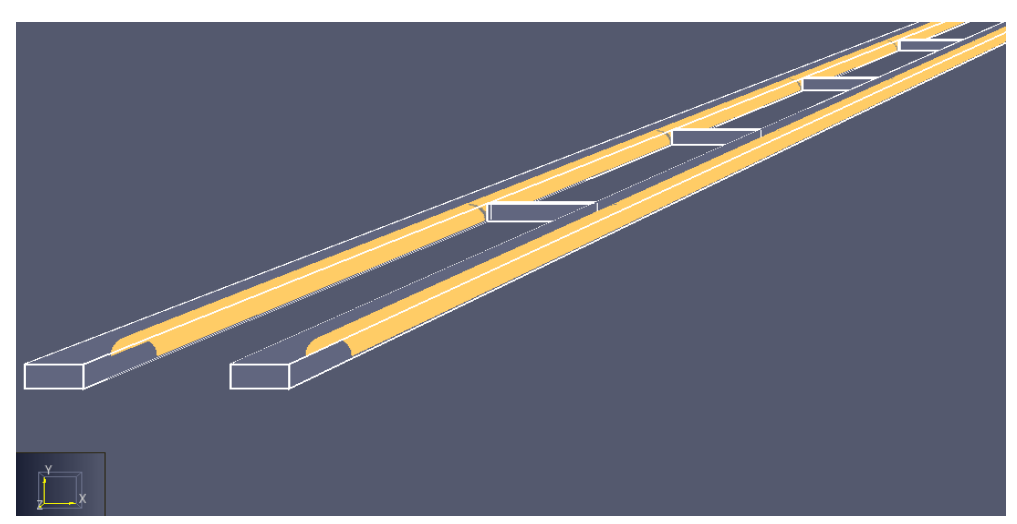

Figure 4. Overall simulation model of extra-long double-hole Tunnel

The model position coordinates are as follows:

Left hole: $(-2, \quad 18)(0, \quad 10)(0, \quad 5653)$

Right hole: $(68, \quad 88)(0, \quad 10)(0, \quad 5681)$

Car lane side hole: $(18, \quad 68)(0,10)(1000, \quad 1010)$

$$
\begin{aligned}
& (18, \quad 68)(0, \quad 10)(1760, \quad 1770) \\
& (18, \quad 68)(0, \quad 10)(2520, \quad 2530) \\
& (18, \quad 68)(0, \quad 10)(3280, \quad 3290) \\
& (18, \quad 68)(0, \quad 10)(4040, \quad 4050) \\
& (18,68)(0, \quad 10)(4800, \quad 4810)
\end{aligned}
$$

Meshing is a key step in FDS calculation and simulation. In order to ensure the accuracy and reliability of the simulation results, as shown in Figure 5, this paper uses a tetrahedral grid to simplify the actual tunnel shape into an arch, which is constructed by 180 small rectangles superimposed along certain arc lines.

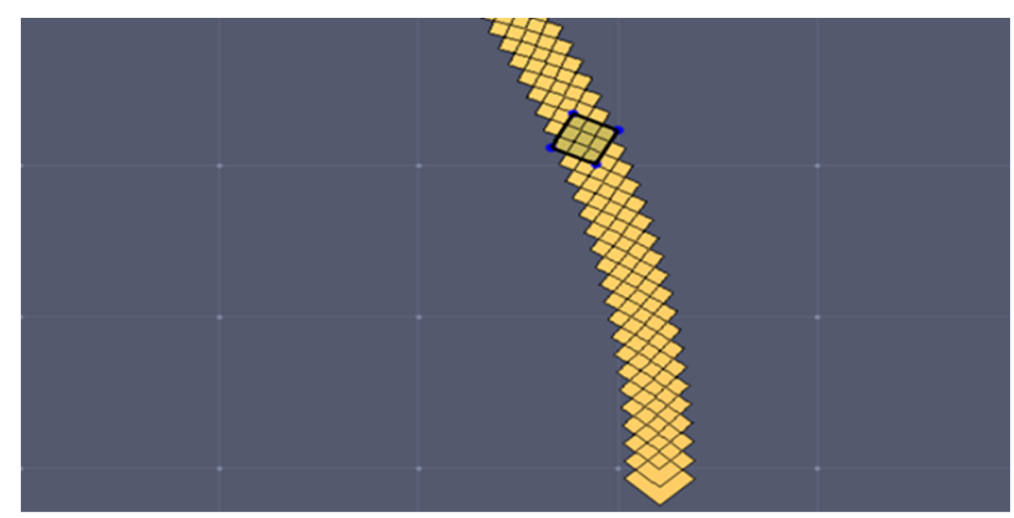




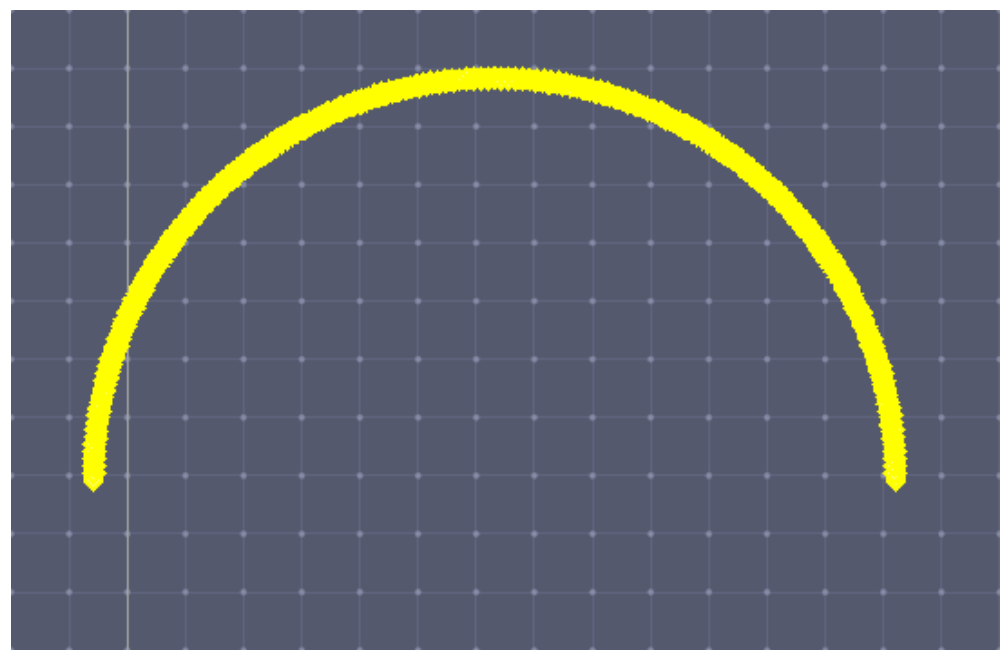

Figure 5. The principle and cross section of model structure

In order to study characteristics of the double-hole tunnel--the influence of the transverse tunnel structure on the spread of smoke and present clear results, this paper selected a 300-meter tunnel with a transverse tunnel with traffic. The location is based on the starting point of the tunnel in Yichang, section $855 \mathrm{~m} \sim 1155 \mathrm{~m}$, and the crosspassages is located at $(1000,1010)$. As shown in Figure 6, the grid model is divided into three parts for calculation. In order to achieve the best accuracy of the left and right interfaces of the cross-passages, the grid size of the connection has been refined, and the grid size is $0.25 \times 0.25 \times 0.25$.
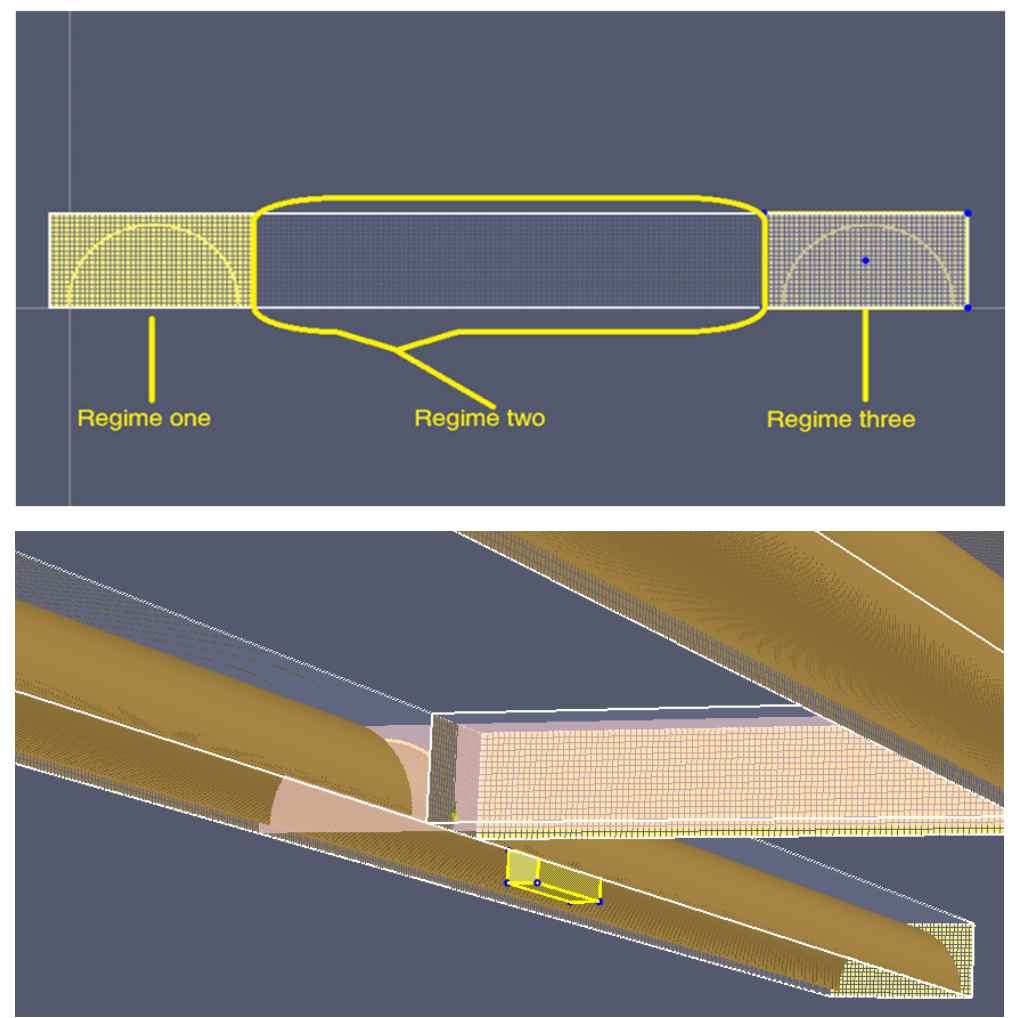

Figure 6. Network model of the extra-long double-hole tunnel

\subsubsection{Location of Fire Source and Monitoring Point}

Most people believe that burns are the leading cause of death in fires. In fact, in most tunnel fire situations, the fire usually does not directly burn the trapped persons, and the injuries mainly come from the continuous release of 
smoke. Flue gas is a mixture of gas and soot, and its composition is very complex (Hu, et al., 2019). Considering that the substances produced by the combustion of different goods are very different, this article chooses the conventional case-mainly hydrocarbons. Among the toxic substances produced by the combustion of hydrocarbons, $\mathrm{CO}$ is more toxic, so the $\mathrm{CO}$ concentration and temperature are selected as the main research objects in this simulation experiment. Three $\mathrm{CO}$ concentration measurement points were established between the fire source and the cross-passages (see Table 2), and three temperature monitoring points were set up along the tunnel transverse direction (see Table 3).

Table 2. Temperature sensor position

\begin{tabular}{|c|c|c|}
\hline Number & Detection parameter & Monitoring position \\
\hline 1 & Temperature $\left({ }^{\circ} \mathrm{C}\right)$ & $\begin{array}{l}1 \text { meter upstream of the fire source and } \\
1.7 \text { meters from the tunnel road surface }\end{array}$ \\
\hline 2 & Temperature $\left({ }^{\circ} \mathrm{C}\right)$ & $\begin{array}{l}30 \text { meters downstream of the fire source and } 1.7 \text { meters from the } \\
\text { tunnel road surface }\end{array}$ \\
\hline 3 & Temperature $\left({ }^{\circ} \mathrm{C}\right)$ & $\begin{array}{l}40 \text { meters downstream of the fire source and } \\
1.7 \text { meters from the tunnel road surface }\end{array}$ \\
\hline
\end{tabular}

Table 3. Co concentration sensor position

\begin{tabular}{crc}
\hline Number & Detection parameter & Monitoring position \\
\hline 1 & CO concentration & 1.5 meters from the center \\
& & line of the cross-passages \\
3 & CO concentration & 1.9 meters from the center \\
& CO concentration & line of the cross-passages \\
& & 2.2 meters from the center \\
\end{tabular}

As shown in Figure 7, the yellow cuboid is the location of the fire source, the green mark is the monitoring point, and the center of the fire source is 42.5 meters from the center line of the cross-passages.

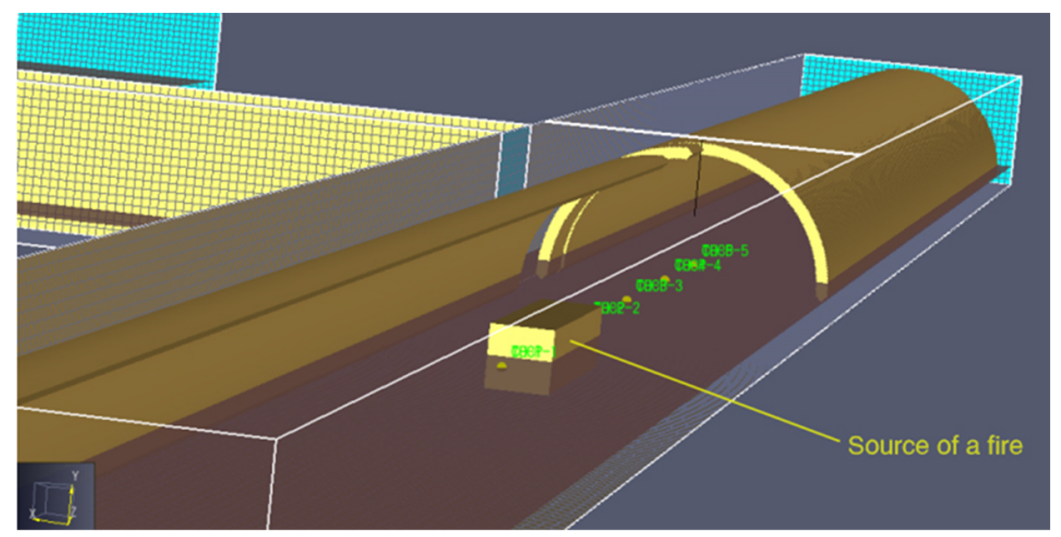

Figure 7. The location of the fire source

\section{Numerical Calculation and Analysis}

\subsection{The Influence of Mechanical Ventilation and Double-Hole Tunnel Structure on Smoke}

After a fire occurs, a lot of heat and toxic smoke will be generated, the diffusion of heat and smoke will not only adversely affect and destroy the structure and auxiliary facilities in the highway tunnel, but also threaten the safety of vehicles and personnel in the tunnel. Mechanical ventilation is generally used instead of natural ventilation, and Jet fans are the key equipment for tunnel ventilation (Bai, et al., 2019). For this reason, this article simulates the 
effect of Jet fans near the fire source. The wind speed is $0.9898 \mathrm{~m} / \mathrm{s}$ with natural ventilation and the tunnel design standard is $3.0 \mathrm{~m} / \mathrm{s}$. If the mechanical ventilation equipment is damaged, natural ventilation can only be used to exhaust the smoke; therefore, the comparison has certain reference value.

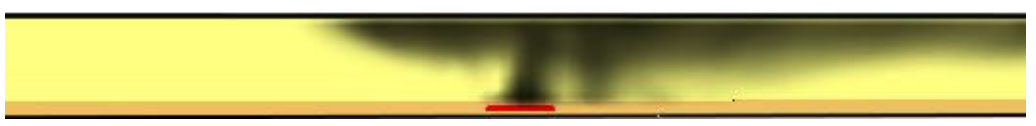

(a) natural wind speed $(0.9898 \mathrm{~m} / \mathrm{s})$

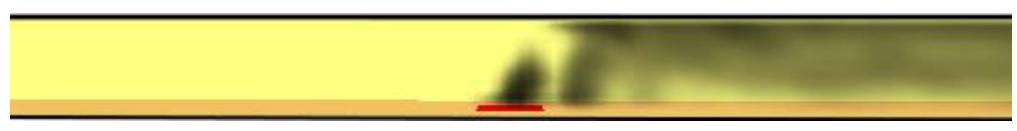

(b)wind speed $(3.0 \mathrm{~m} / \mathrm{s})$

Figure 8. Flue gas flow chart at different wind speeds.

As shown in Figure 8, under natural wind speed, the flue gas will flow back, which is very unfavorable for the control of fire smoke. When the wind speed is $3.0 \mathrm{~m} / \mathrm{s}$, the smoke transmission along the tunnel does not produce vortex and backflow, which meets the critical speed required by the tunnel exhaust design. In the following tunnel simulation process, the wind speed of $3.0 \mathrm{~m} / \mathrm{s}$ will be exhausted near the fire source by default.

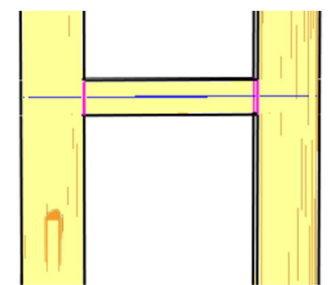

$2.1 \mathrm{~s}$

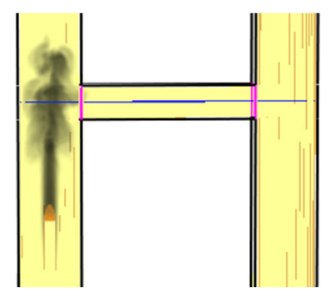

$9.9 \mathrm{~s}$

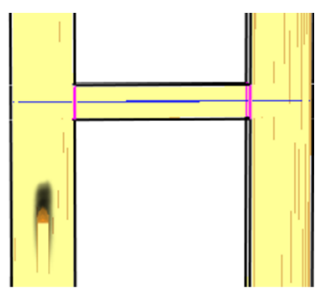

$3.3 \mathrm{~s}$

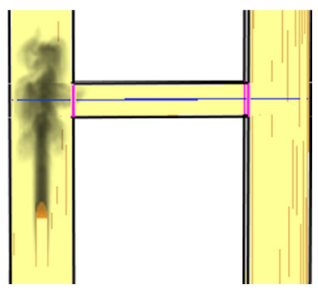

$10.5 \mathrm{~s}$

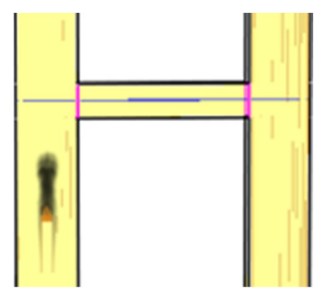

$4.2 \mathrm{~s}$

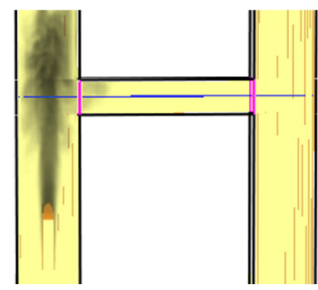

$13.8 \mathrm{~s}$

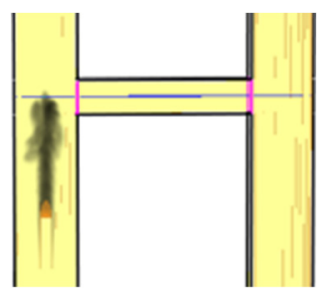

$6.6 \mathrm{~s}$

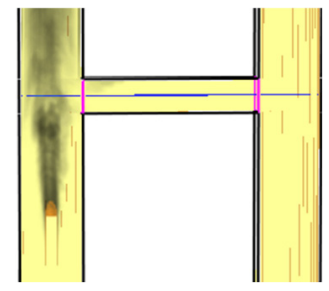

$26.1 \mathrm{~s}$

Figure 9. Changes in the flow of smoke at the cross-hole

When a fire occurs in a double-hole tunnel, in addition to the effect of wind speed on the flow of smoke, the structure of the double-hole tunnel itself, such as the Cross-passages structure, will also affect the flow of smoke. The cross-passages itself can be used for personnel escape and post-disaster rescue, but if smoke enters the crosspassages along with the airflow, it will pose a huge threat to the evacuation of personnel. Therefore, this paper simulated the smoke flow of the 300-meter double-hole tunnel after the fire, and the results are shown in Figure 9. About 3 seconds after the fire, the smoke has been generated. The upstream of the fire is a safe zone and is not affected by the smoke; the downstream of the fire source increases with time, and the smoke diffuses rapidly; when 6.6 seconds, the smoke has reached the center position of double hole (the position of the red line in the figure); after that, the main part of the flue gas continues to spread downstream across the cross-passages, and finally enters a stable stage, with only a small amount of flue gas finally entering the cross-passages.

Then the right hole and the sidewalk hole is "removed" to better observe the flow path of the smoke. As shown in the top view of the flue gas path in Figure 10, the pink border represents the interface of the cross-passages, and the boundary conditions at the opening are retained, and the flue gas temperature is marked with color. 

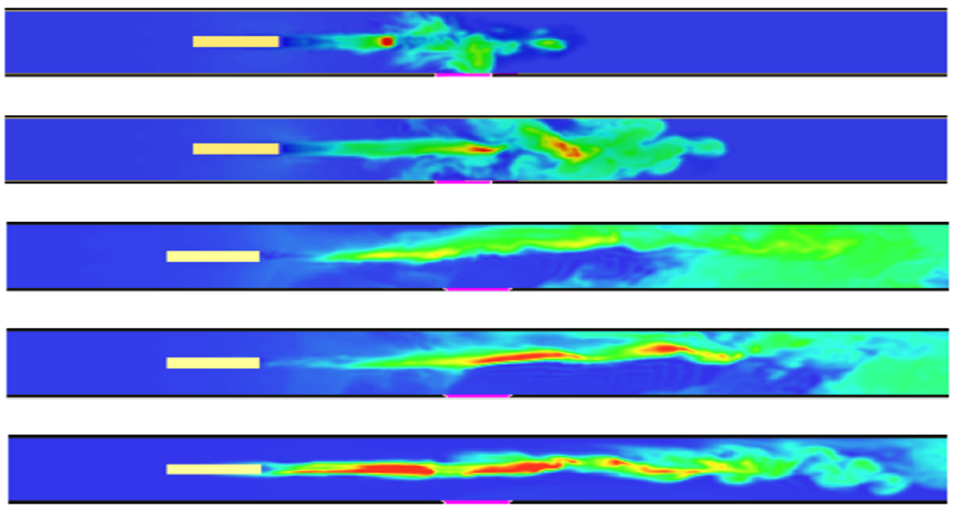

Figure 10. Smoke distribution at the cross-hole

As can be seen in the figure, when the flue gas initially passes through the opening of the cross-passages, it is turbulent and accompanied by a small vortex. According to Figure 9, the flue gas has entered the cross-passages for a short time. As time goes by, the flue gas is affected by the lateral wind, and the small vortex continues to expand, again bringing the flue gas back to a small extent. After that, the flue gas will continue to advance downstream, and gradually leave the cross-passages to shift to the left, and finally the flue gas is in a stable state. Generally speaking, the flue gas will not have a major impact on the cross-passages.

\subsection{Temperature Analysis}

High temperature and smoke can both do serious harm to the human body, such as causing burns or promoting acute cardiovascular and cerebrovascular diseases. Since the smoke diffuses rapidly in the left tunnel, if the evacuated personnel are close to the fire source and are injured by the high temperature while escaping downstream, the situation would be very dangerous. This paper simulates the temperature changes at three monitoring points in the cross-passages and the tunnel to analyze the temperature changes in the double-hole tunnel structure.

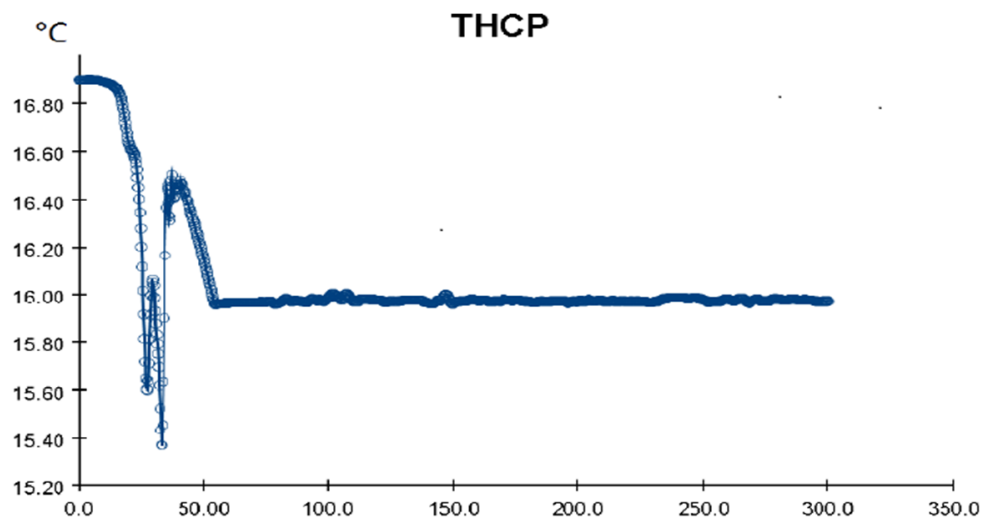

Figure 11. The change curve of temperature sensor position 1

As shown in Figure 11, one meter upstream of the fire source, if a fire occurs, the highest temperature will be the initial ambient temperature in the tunnel, and the temperature will drop to a certain extent over time. And the lowest temperature is $15.4^{\circ} \mathrm{C}$. This change indicates that the fire absorbs a lot of heat around it. The temperature of the monitoring point fluctuates and changes, and stabilizes after 50 seconds, maintaining around $16^{\circ} \mathrm{C}$, which shows that it is safe to be upstream of the fire point. 

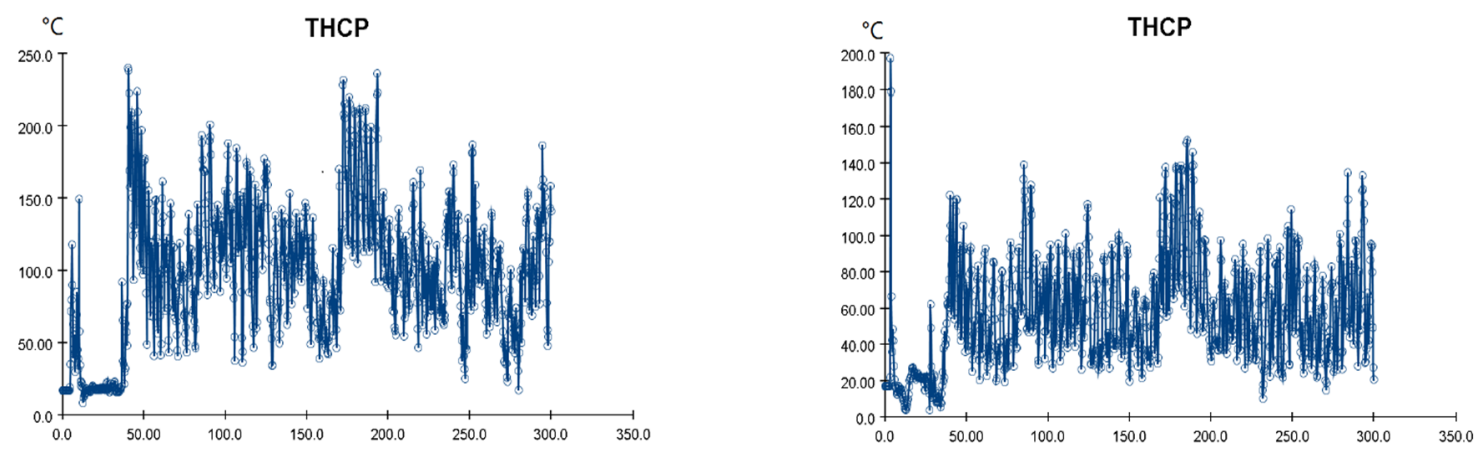

Figure 12. The change curve of temperature sensor position 2 and 3

It can be seen from the temperature changes of the monitoring points before and after the cross-passages, the temperature of the two monitoring points is relatively high, the temperature control point 2 is located in front of the cross-passages, and the maximum temperature of the monitoring point is $250^{\circ} \mathrm{C}$. Combining the same longitudinal axis in point 3 , it is known that the temperature at the bottom of the tunnel is relatively low, and the temperature measurement point 3 is relatively far from the fire source, which is equivalent to the measurement point 2 being slightly lower and the highest temperature is only 200 degrees, but it is still harmful to the human body. It proves that the temperature in the tunnel decreases significantly with the increase of the distance from the fire source, making it the most feasible way to move away from the fire source quickly after the fire.

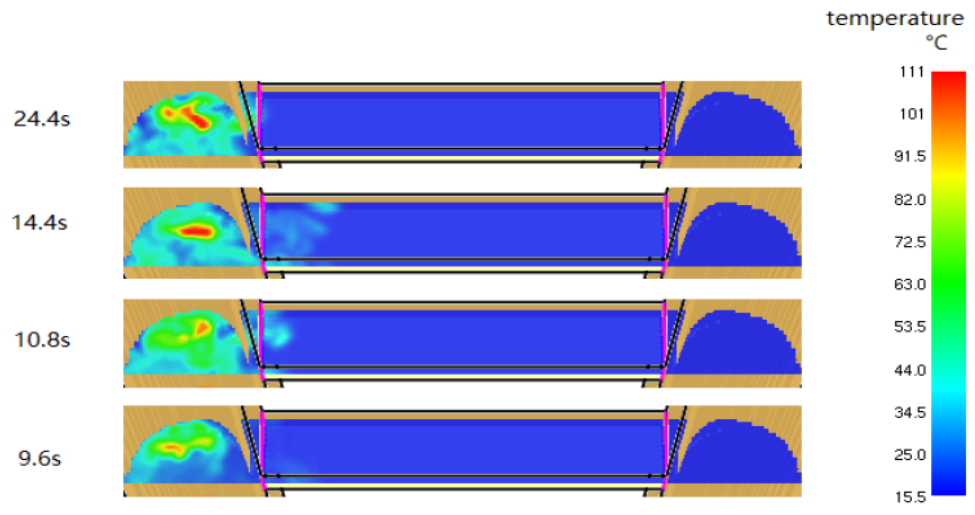

Figure 13. Cross-hole flue gas cut surface

For the cross-passages, after the fire, it can be seen from Figure 9 that the smoke reached the position of the crosspassages 35 meters away from the fire source at $6.6 \mathrm{~s}$, and the average speed of smoke spread was about $5.3 \mathrm{~m} / \mathrm{s}$. With reference to Figure 13, it can be inferred that the smoke will spread into the cross-passages in a small amount. At the entrance of the cross-passages near the left tunnel, the temperature will rise to $34.5^{\circ} \mathrm{C} \sim 44^{\circ} \mathrm{C}$ for a short time. This shows that the high temperature is concentrated in the main road, while the hole just has little effect. According to the revised Cranee formula (Cranee), the human body can withstand the temperature, and the temperature in the cross-passages will not cause harm to the human body (Xia, et al., 2009). On the left tunnel at the cross-passages, the temperature in the central area will reach $111^{\circ} \mathrm{C}$, which makes short stays may cause harm to the human body. The cross-passages is obviously safer than the tunnel in terms of temperature. It is recommended that the evacuees downstream of the fire should choose to leave the cross-passages, or be far enough away, and also pay attention to avoid the possible stampede in the smoke.

Table 4. Temperature tolerance of the body

\begin{tabular}{ccccccc}
\hline Temperature & $35.41^{\circ} \mathrm{C}$ & $46.65^{\circ} \mathrm{C}$ & $65.80^{\circ} \mathrm{C}$ & $100{ }^{\circ} \mathrm{C}$ & $140^{\circ} \mathrm{C}$ & $150^{\circ} \mathrm{C}$ \\
\hline Tolerance time & $13.72 \mathrm{~h}$ & $5.07 \mathrm{~h}$ & $1.47 \mathrm{~h}$ & $19 \mathrm{~min}$ & $5.76 \mathrm{mim}$ & $<5 \mathrm{~min}$ \\
\hline
\end{tabular}




\subsection{CO Concentration Analysis}

Toxic gas is different from the thick smoke visible to the human eye and the temperature change that can be clearly noticed. It exists not only in the thick smoke but also in the air, and some are even colorless and tasteless, making it difficult for personnel to detect this potential danger, so toxic substances in the fire caused numerous casualties.

Tunnel fires will produce a lot of toxic substances, such as CO, nitrogen oxides, aldehydes, hydrogen cyanide, sulfur dioxide (Li. 2010), etc. Among these substances, some irritating substances can cause harm to human lung tissues, and some can irritate eyes or paralyze nerves. Taking into account the uncertainty of the combustion material in the accident and the relatively confined space, $\mathrm{CO}$, as the main product of incomplete combustion of hydrocarbons, Is a major factor in the measurement of toxic products. Therefore, this paper simulates and analyzes the change of $\mathrm{CO}$ concentration around the entrance of the cross-passages.

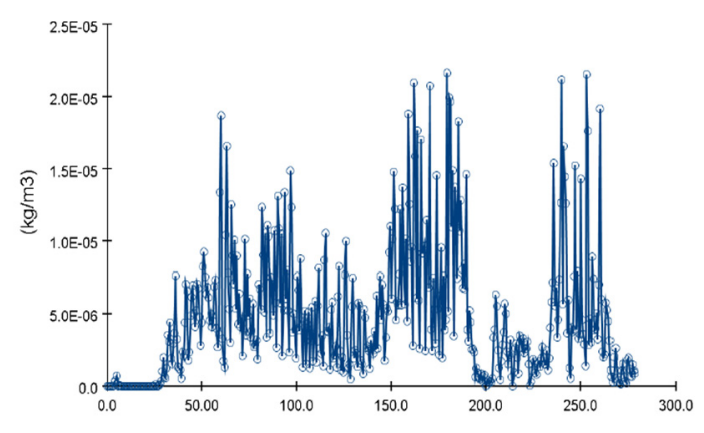

(a)monitoring points 1

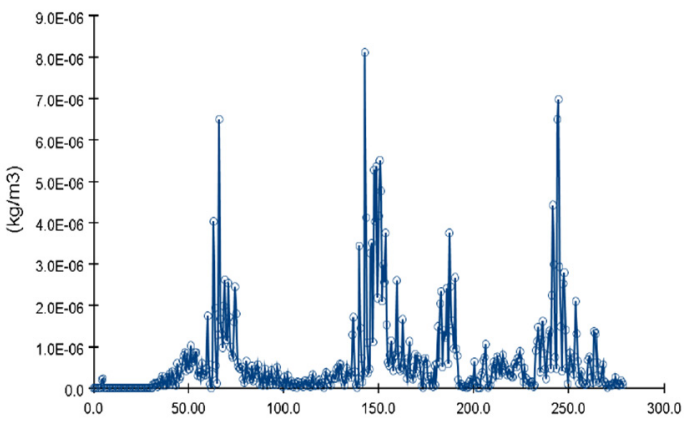

(b) monitoring points 2

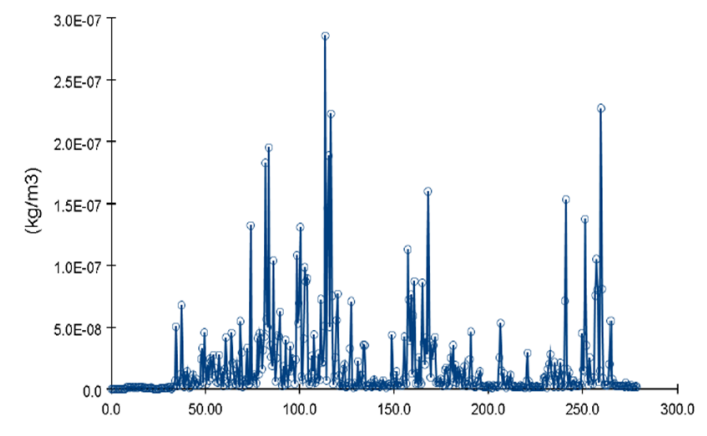

(c)monitoring points 3

Figure 14. The change curve of co concentration of each monitoring point

It can be seen from Figure 14 that from the start of the fire to the stabilization of the fire, during the whole process, the growth rate of $\mathrm{CO}$ concentration at the beginning of each measurement point at the cross-passages is slightly less than the growth rate of $\mathrm{CO}$ concentration after the steady state. This shows that in the early stage of fire development. The $\mathrm{CO}$ concentration will not threaten the life safety of the people in the cross-passages in a short time (Sojoudi, et al., 2014).

In terms of $\mathrm{CO}$ concentration characteristics, there were three obvious peaks in the concentration at each monitoring points, with the highest value appearing at 150 seconds of the monitoring points 1, up to 17.59 PPM. The distance between the point 1 and the point 3 is only 0.7 meters, and the $\mathrm{CO}$ concentration differs by two orders of magnitude, and the concentration is 0.23 PPM. Generally speaking, most cross-passages are within the safe range of CO human bearing (Yong, et al., 2006). The farther the CO concentration is from the main tunnel horizontal, the lower the $\mathrm{CO}$ concentration will be, and the closer it is to the tunnel center line, the more dangerous the $\mathrm{CO}$ concentration may be. 
Table 5. The co bear of the human body

\begin{aligned} & \hline Gas concentration $(\mathrm{ppm})$ Hazard \\ & \hline 50 Allowable human exposure, could be exposed for 8 hours. \\ & May cause mild forehead headache within 2-3 hours. \\ & 400 $\begin{array}{l}\text { Headache and vomiting on the forehead 1-2 hours later, } \\ \text { dizziness after 2.2 to 3.5 hours. }\end{array} \\ & 800 \begin{array}{l}\text { Headache, dizziness, vomiting within 45 minutes, } \\ \text { coma within 2 hours, and possibly death. } \\ \text { Headache, dizziness, vomiting within 20 minutes, } \\ \text { coma and death within 1 hour. }\end{array} \\ &$\hline\end{aligned}

\subsection{Safety Prevention and Control Measures}

In the $300 \mathrm{~m}$ long double-hole tunnel model intercepted in this article, it is assumed that the cross-passages is not far downstream from the fire source, but it is also necessary to consider the scene where the fire source is far from the cross-passages, that is, the nearest cross-passages is located at the fire source. The upstream or next crosspassages is very far from the fire source. In such a situation, it is necessary for personnel to be far enough away from the fire source and unable to enter the cross-passages immediately, and to consider the adverse conditions such as reduced visibility, high temperature, and people tending to feel intense in the fire. The problem needed to be solved -"How to get more safe escape time (ASET) for personnel". Here the author chose the air curtain as the prevention and control method of the main tunnel to simulate whether its function of controlling the transmission of smoke is beneficial to control the high-temperature airflow and $\mathrm{CO}$ gas.

Air curtain is a kind of prevention and control equipment composed of air handling equipment, ventilators, air duct systems and air distributors, and is often used in theaters, shopping malls, warehouses and other places (Gupta, et al., 2007; Severino, et al., 2020). When the air curtain is opened, it can block the air on both sides to prevent dust and prevent the spread of smoke, without affecting the evacuation of personnel and fire rescue. Commonly used air curtains for industrial plants include S GRM d type and Q GRM d type. In order to test their feasibility in blocking tunnel fires, this paper only sets up a $6 \mathrm{~m} / \mathrm{s}$ jet velocity and a $0 \mathrm{~m} / \mathrm{s}$ blank sample for comparative analysis. The air curtain is located behind the cross-passages, $54.5 \mathrm{~m}$ downstream of the fire source. The air curtain jet size is set to $11.2 \mathrm{~m} \times 2 \mathrm{~m}$, and the $\mathrm{CO}$ concentration and temperature monitoring points are set behind it. Refer to the table below for detailed locations.

Table 6. The position of the sensor

\begin{tabular}{cll}
\hline Number & Detected object & Detector position \\
\hline 1 & Temperature & 3 meters downstream of the air curtain \\
& & and 1.6 meters above the ground \\
2 & CO concentration & 3 meters downstream of the air curtain, \\
& 1.6 meters above the ground \\
\hline
\end{tabular}

The following two sets of comparison data line graphs are obtained through simulation 


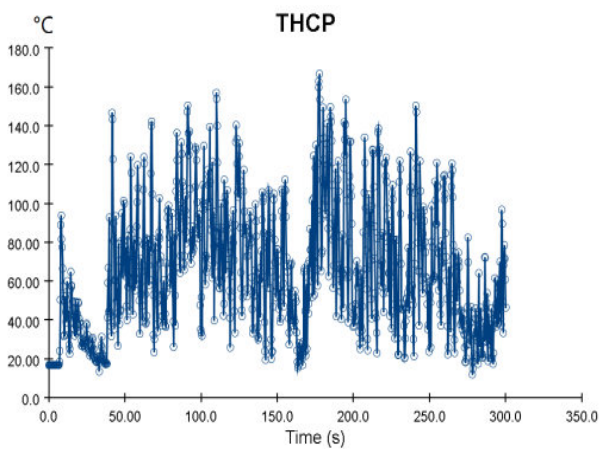

(a)monitoring points $1(0 \mathrm{~m} / \mathrm{s})$

co

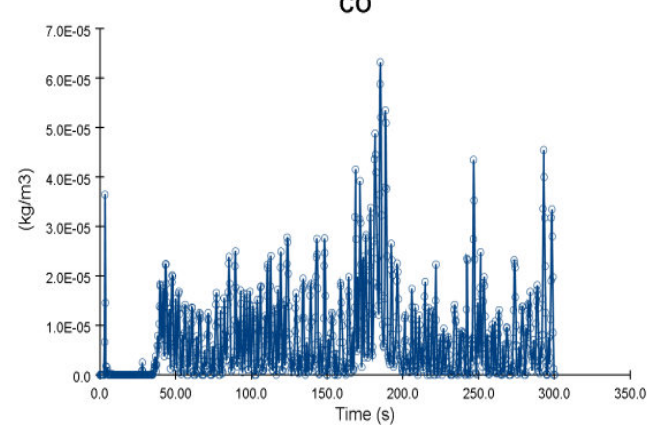

(c)monitoring points $2(0 \mathrm{~m} / \mathrm{s})$

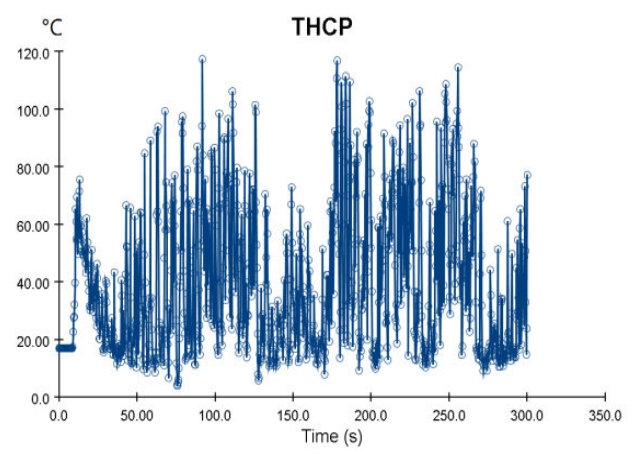

(b)monitoring points $1(6 \mathrm{~m} / \mathrm{s})$

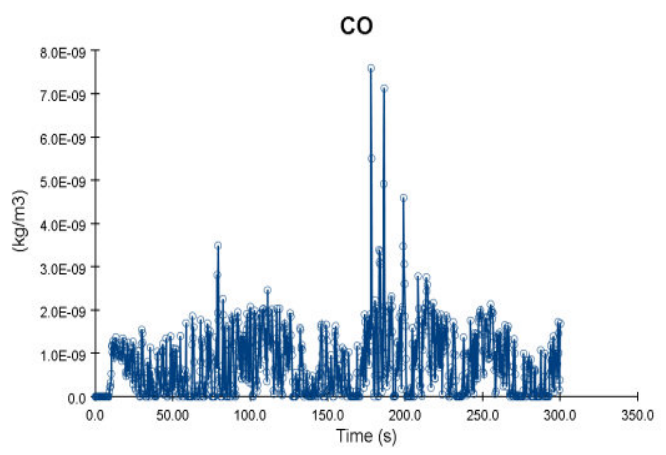

(d)monitoring points $2(6 \mathrm{~m} / \mathrm{s})$

Figure 15. Before and after the air curtain, the $\mathrm{CO}$ concentration varies with the wind speed

As shown in Figure 15 (a) and (b) under the state of no air curtain, the temperature change of monitoring point 1 changes more than when there is an air curtain; the concentration interval of the temperature gradient is from $50 \sim$ $140^{\circ} \mathrm{C}$ dropped to $20 \sim 80^{\circ} \mathrm{C}$, the peak value dropped from $170^{\circ} \mathrm{C}$ to $120^{\circ} \mathrm{C}$, showing that the air curtain also has a significant temperature insulation effect. From Figure 16 (c) and (d), it can be seen that the CO concentration changes from a large fluctuation without an air curtain to a relatively stable condition with an air curtain of $6 \mathrm{~m} / \mathrm{s}$. The main range of $\mathrm{CO}$ concentration was reduced from $0 \sim 2.0 \times 10^{-5} \mathrm{~kg} / \mathrm{m} 3$ by nearly two quantity sets, which proved that the air curtain can effectively reduce the risk of $\mathrm{CO}$ poisoning and injured by the high temperature when people escape.

\section{Conclusion}

This paper takes the Jieling tunnel project in Yichang City, Hubei Province as 3, adopts the ATA method to analyze the cause of the tunnel fire, and converts the cause into a fire source model, and brings it into the FDS software to simulate the Jieling tunnel model. The section of the tunnel $(855 \sim 1155 \mathrm{~m}$ of the tunnel, 300 meters in total) as a simplified model of the extra-long double-hole tunnel structure. The simplified model is used to numerically simulate the three influencing factors (smoke, temperature, toxic gas) that hinder the escape of personnel, and it is concluded that the horizontal structure of the double-hole tunnel is beneficial to the escape of personnel. Finally, the positive significance of the air curtain to extend the escape time at a long distance is analyzed. The specific conclusions are as follows.

(1) There are 14 sets of basic event combinations leading to road tunnel fire accidents. Among them, there are 8 sets of events related to the two basic causes of vehicle fire and cargo fire, freight trucks are one of the main sources of danger.

(2) Under the wind speed of $3.0 \mathrm{~m} / \mathrm{s}$, which is the design standard of highway tunnel ventilation (the same below), the diffusion speed of smoke in the tunnel is very fast $(7 \mathrm{~m} / \mathrm{s})$. In the initial stage of the fire, the flue gas is affected by the cross-passages, and only a small part of the flue gas enters it. After that, the flue gas enters a stable state. All in all, the cross-passages is basically not affected by the flow of smoke, and the cross-passages is more conducive to personnel escape than the main cave. 
(3) In the tunnel, the temperature at the upstream position of the fire source is basically unchanged. Below the fire source, the temperature at the center of the tunnel rises rapidly after the fire, but it will decrease rapidly as the distance from the fire source increases. In the cross-passages, the temperature is less affected by that of the tunnel, so it is safer than the main tunnel.

(4) The $\mathrm{CO}$ concentration at the entrance of the cross-passages is greatly affected by time and horizontal distance. The closer it is to the centerline of the tunnel, the more dangerous it is. Cross-passages appears to be safer than main tunnel.

(5) Finally, considering factors such as the randomness of the tunnel fire location, field of view, high temperature, and toxic gas concentration, it is often difficult for personnel to enter the nearby cross-passages when escaping, which requires smoke control devices to blocking some harmful factors, comparative analysis proves that the air curtain can effectively control the flue gas transmission, reduce the downstream temperature and the concentration of $\mathrm{CO}$ poisonous gas. Therefore, it is recommended to install air curtains in extra-long tunnels to gain more escape time.

\section{Acknowledgments}

The authors are grateful for financial support from the Transport Science and Technology \& Achievement Transformation Preliminary project approval of Jiangsu Province (2018Z21).

\section{References}

Bai, Z. P., Li, Y. F., \& Li, J. M. (2019). Numerical Study the Performance of Jet Fans in Utility Tunnel Ventilation// 2019 International Conference on Intelligent Transportation, Big Data \& Smart City (ICITBS). https://doi.org/10.26914/c.cnkihy.2019.055901

Brinckerhoff BP. (2005). Memorial tunnel fire ventilation test program. Comprehensive test report, Massachusetts Highway Department.

Cheong, M. K., Cheong, W. O., Lemaire, A. D., \& Noordijk, L. M. (2014). Heat Release Rate of Heavy Goods Vehicle Fire in Tunnels with Fixed Water Based Fire-Fighting System. Fire Technology., 50(2), 249-266. https://doi.org/10.1007/s10694-013-0367-0

Chow, W. K., Gao, Y., Zhao, J. H., Dang, J. F., Chow, C. L., \& Miao, L. (2015). Smoke movement in tilted tunnel fires with longitudinal ventilation. Fire Safety Journal., 75 , 14-22. https://doi.org/10.1016/j.firesaf.2015.04.001

Elice-Cortes, J. C., Molina, N., Severino, A., Severino, G., Fuentes, A., \& Rojas, P. (2020). Turbulent transport mechanisms on the heat confinement in tunnels by using low-velocity air curtains. Applied Thermal Engineering., 118, 115852. https://doi.org/10.1016/j.applthermaleng.2020.115852

GB/T3730.1 - 2001. (2001). Motor Vehicles and Trailers-Types-Terms and Definitions. National Technical Committee of Auto Standardization. (Chinese Standard)

Gehandler, J., Eymann, L., \& Regeffe, M. (2015). Limit-Based Fire Hazard Model for Evaluating Tunnel Life Safety. Fire Technology., 51(3), 585-614. https://doi.org/10.1007/s10694-014-0406-5

Gu, X. C., Zhang, J. D., Pan, Y., Ni, Y.Q., Ma, C., Zhou, W., \& Wang, Y. Y. (2020). Hazard analysis on tunnel hydrogen jet fire based on CFD simulation of temperature field and concentration field. Safety Science., 122, 104532. https://doi.org/10.1016/j.ssci.2019.104532

Gupta, S., Pavageau, M., \& Elicer-Cortes, J. C. (2007). Cellular confinement of tunnel sections between two air curtains. Building and Environment., 4(29), 3352-3365. https://doi.org/10.1016/j.buildenv.2006.08.026

Harish, R., \& Venkatasubbaiah, K. (2014). Effects of buoyancy induced roof ventilation systems for smoke removal in tunnel fires. Tunnelling and Underground Space Technology., 42, 195-205. https://doi.org/10.1016/j.tust.2014.03.007

Hitoshi, K., Yasushi, O., Hiroomi, S., \& Osami, S. (2003). Fire properties in near field of square fire source with longitudinal ventilation in tunnels. Fire Safety Journal., 38, 319-340. https://doi.org/10.1016/S03797112(02)00089-9

Horikoshi, K. (2009). An Examination on Smoke Control by Means of Numerical Simulation in a Long Urban Tunnel[C]. 13th Road Engineering Association of Asia and Australasia Conference., Korea. https://doi.org/10.1177/1042391503013001002

Hu, X., Zhou, H. J., \& Yang, F. (2019). Study on the Influence of Fire Smoke on the Design of Urban Rail Transit 
Safety Evacuation System. Henan ence and Technology.

JTG/T D70/2-02-2014. (2014). Detailed Rules of highway Tunnel Ventilation Design. China Communications Press Co., Ltd. (Chinese Standard)

Laurent, G., \& Bertrand, G. (2018). Fault tree analysis and risk mitigation strategies for mine hoists. Safety Science., 110, 222-234. https://doi.org/10.1016/j.ssci.2018.08.010

Li, Y. Z., Lei, B., \& Ingason, H. (2013). Theoretical and Experimental Study of Critical Velocity for Smoke Control in a Tunnel Cross-Passage. Fire Technology., 49(2), 435-449. https://doi.org/10.1007/s10694-010-0170-0

Li, Z. H. (2010). Toxic Mechanism and First Aid Measures of Common Harmful Combustion Products. Safety and Environmental Engineering., 017(003), 93-96, 101. https://doi.org/CNKI:SUN:KTAQ.0.2010-03-023 (in Chinese)

Lin, C. J., \& Chuah, Y. K. (2008). A study on long tunnel smoke extraction strategies by numerical simulation. Tunnelling \& Underground Space Technology Incorporating Trenchless Technology Research., 23(5), 522530. https://doi.org/10.1016/j.tust.2007.09.003

Max, K., Daniel G., Philipp, G., Susanne, B., Mathias, M., Michael, J., Markus, N., Andreas, M., \& Paul, P. (2015). The effect of dangerous goods transporters on hazard perception and evacuation behavior - A virtual reality experiment on tunnel emergencies. Fire Safety Journal., 78, 24-30. https://doi.org/10.1016/j.firesaf.2015.07.002

Mcgrattan, K. B., Mcdermott, R. J., Weinschenk, C. G., \& Forney, G. P. (2013). Fire Dynamics Simulator, User's Guide. Nist Special Publication.

NFPA 502-2017. (2017). Standard for Road Tunnels, Bridges, and Other Limited Access Highways. America: USNFPA.

PIARC Committee on Road Tunnels. (1999). Fire and Smoke Control in Road Tunnels. France: PIARC.

Sojoudi, A., Afshin, H., \& Farhanieh, B. (2014). An analysis of carbone monoxide distribution in large tunnel fires. Journal of Mechanical ence \& Technology., 28(5), 1917-1925. https://doi.org/10.1007/s12206-014-0339-4

Soufien, G., \& Rejeb, B. M. (2017). CFD analysis of smoke blacklayering dispersion in tunnel fires with longitudinal ventilation. Fire and Materials., 41(6), 598-613. https://doi.org/10.1002/fam.2394

Vauquelin, O., \& Telle, D. (2005). Definition and experimental evaluation of the smoke "confinement velocity" in tunnel fires. Fire Safety Journal., 40, 320-330. https://doi.org/10.1016/j.firesaf.2005.02.004

Xia, Y. X., Zhou, Y. D., \& Wang, Y. D. (2009). Study on escape of people in highway tunnel fire. China Civil Engineering Journal., 8, 115-123. https://doi.org/CNKI:SUN:TMGC.0.2009-08-017 (in Chinese)

Xu, X. Y., Li, Y. Z., Xu, Z. Y., Li, Z. (2010). Control effect of smoke in different opening situations in a highbuilding stairwell. Journal of University of ence and Technology of China., 40(10), 1036-1042. https://doi.org/10.3969/j.issn.0253-2778.2010.10.008

Yong, A. L., Yang, G. S., \& Peng, L. M. (2006). Research on the Mechanism of CO Hazards to Personnel in Tunnel Fire. Mining Technology., 006(003), 412-414. https://doi.org/10.13828/j.cnki.ckjs.2006.03.126 (in Chinese)

Zhuang, Y. H., Ding, H., Zheng, G. P., Cui, Y. K., \& Huang, Y. (2020). Study on Ventilation System Linkage Control Strategy in a Double-Hole Tunnel Fire. Advances in Materials Science and Engineering., 5, 1-14. https://doi.org/10.1155/2020/5163632

\section{Copyrights}

Copyright for this article is retained by the author(s), with first publication rights granted to the journal.

This is an open-access article distributed under the terms and conditions of the Creative Commons Attribution license (http://creativecommons.org/licenses/by/4.0/). 